FACULdADE DE CIÊNCIAS ECONÔ MICAS DA UFRGS

MACROECONOMIA DO BRASIL PÓS-1994 LUIZ CARLOS BRESSER-PEREIRA

DESENVOLVIMENTO ECONOMMICO, PREFERÊNCIA PELA LIQUIDEZ E ACESSO BANCÁRIO: UM ESTUDO DE CASO DAS MESORREGIÓES DE MINAS GERAIS

MARCO CROCCO, CLAUDIO BARRA DE CASTRO, ANDERSON CAVALCANTE E VANESSA DA COSTA VAL

FRIEDMAN E O MONETARISMO: A VELHA TEORIA QUANTITATIVA DA MOEDA E A MODERNA ESCOLA MONETARISTA

GENTIL CORAZZAE RODRIGO L. KREMER

BOLLHAS RACIONAIS, CICLO DE PREÇOS DE ATIVOS E RACIONALIDADE LIMITADA: UMA AVALIACAOO CRITICA DOS MODELOS NEOCLÁSSICOS DE BOLHAS ESPECULATIVAS JOSÉ LUIS OREIRO

VULNERABILITY INDICATORS OF THE TWIN CRISES: THE EAST ASIAN EPISODE

TITO BELCHIOR SILVA MOREIRA

IMPACTOS POTENCIAIS DA NEGOCIAÇÃO DA ALCA SOBRE OS INVESTIMENTOS EXTERNOS EM SERVIÇOS PROFISSIONAIS NO BRASIL

MICHEL ALEXANDRE, OTAVIANO CANUTO E GILBERTO TADEU LIMA

TEORIA MARXISTA DO VALOR: UMA INTRODUÇẢO ALFREDO SAAD FILHO

UM ESTUDO EMPIRICO DOS CICLOS POLITICO. ECONOOMICOS NO BRASIL

ATHOS PRATES DA SILVEIRA PREUSSLER E MARCELO SAVINO PORTUGAL

RELENDO CHANDLER, WILLIAMSON E NORTH PARA ENTENDER O PROCESSO DE FORMACĀO DAS ESTRADAS DE FERRO NO BRASIL

JEFFERSON ANDRONIO RAMUNDO STADUTO

WEIMAR FREIRE DA ROCHA IR. E CLAIITON ATAIDES DE FREITAS

MATRIZ DE INSUMO-PRODUTO PARA A ECONOMIA TURISTICA BRASILEIRA: CONSTRUCCÃO E ANÁLISE DAS RELAÇÓES INTERSETORIAIS

FRANCISCO CASIMIRO FILHO E JOAQUIM JOSÉ MARTINS GUILHOTO

SEÇĀO ESPECIAL: AVALIAÇŌES INICIAIS DA POLITTICA ECONÓMICA DO GOVERNO LULA

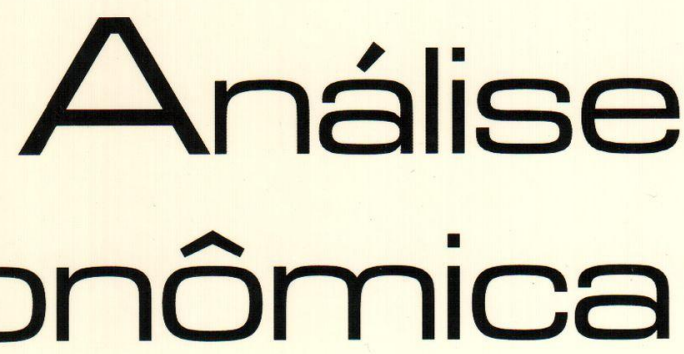


Universidade Federal do Rio Grande do Sul

Reitora: Profa. Wrana Maria Panizzi

Faculdade de Ciencias EConómicas

Diretora: Prof Pedro César Dutra Fonseca

Centro de Estudos e Pesquisas Economicas

Diretor: Prof. Gentil Corazza

Departamento de Ciéncias económicas

Chiefe: Prof. Ricardo Dathein

Curso de Pós. Graduação em Economia

Coordenador: Prof. Eduardo Pontual Ribeiro

Programa de Pós-Graduação em Desenvolvimento Rural

Coordenador: Prof. jalcione Almeida

CONSElHo EDITORIAL:

Carlos G. A. Mielitz Netto (UFRGS), Eduardo A. Maldonado Filho (UFRGS), Eduardo P. Ribeiro (UFRGS), Eleutério F. S. Prado (USP), Eugênio Lagemann (UFRGS), Fernando Cardim de Carvalho (UFRJ), Fernando Ferrari Filho (UFRGS), Fernando de Holanda Barbosa (FGV/RJ), Flávio Vasconcellos Comim (UFRGS), Gentil Corazza (UFRGS), Giácomo Balbinotto Netto (UFRGS), Gustavo Franco (PUC/RJ), Jan A. Kregel (UNCTAD), João Rogério Sanson (UFSC), Joaquim Pinto de Andrade (UnB), Jorge Paulo Araújo (UFRGS), Marcelo S. Portugal (UFRGS), Maria Alice Lahorgue (UFRGS), Paul Davidson (University of Tennessee), Paulo D. Waquil (UFRGS), Pedro C. D. Fonseca (UFRGS), Philip Arestis (Levy Economics Institut of Bard College), Roberto C. de Moraes (UFRGS), Ronald Otto Hillbrecht (UFRGS), Sabino da Silva Porto Jr. (UFRGS), Stefano Florissi (UFRGS) e Werner Baer (University of Illinois at UrbanaChampaign).

COMISSÃO EDITORIAL:

Eduardo Augusto Maldonado Filho, Fernando Ferrari Filho, Gentil Corazza, Marcelo Savino Portugal, Paulo Dabdab Waquil e Roberto Camps Moraes.

EDIroR: Prof. Fernando Ferrari Filho

Editor Adunnio: Prof. Gentil Corazza

SECRETÁrla: Clarissa Roncato Baldim

REVISÁO DE TEXTOS: Vanete Ricacheski

EDITORaÇão Eletrónica: Vanessa Hoffmann de Quadros

Fundador: Prof Antônio Carlos Santos Rosa

Os materiais publicados na revista Análise Econômica são da exclusiva responsabilidade dos autores. É permitida a reprodução total ou parcial dos trabalhos, desde que seja citada a fonte. Aceita-se permuta com revistas congêneres. Aceitam-se, também, livros para divulgação, elaboraçāo de resenhas e recensōes Toda correspondência, material para publicaçāo (vide normas na terceira capa), assinaturas e permutas devem ser dirigidos ao seguinte destinatário:

Análise Econômico

PROF FERNANDO FERRARI FILHO Revisła Análise Econômica - Av. João Pessoa, 52 CEP 90040-000 PORTO ALEGRE - RS, BRASL Telefones: (051) 316-3513 - Fax: (051) 316-3990 E-mail: rae@ufrgs.br

Ano 21, $n^{\circ} 39$, março, 2003 - Porto Alegre

Faculdade de Ciências Econômicas, UFRGS, 2003

Periodicidade semestral, março e setembro.

Tiragem: 500 exemplares

1. Teoria Econômica - Desenvolvimento Regional.

Economia Agrícola - Pesquisa Teórica e Aplicada -

Periódicos. I. Brasil

Faculdade de Ciências Econômicas,

Universidade Federal do Rio Grande do Sul 


\section{O Governo Lula e a Manutenção da Agenda da Política Macroeconômica}

Aod Cunha de Moraes $J r^{*}$

\section{Introdução}

Erigir o crescimento como meta de política econômica não parece revelar muito sobre esta. A não ser o óbvio. Algo como dizer que ser feliz é preferivel a ser infeliz. Axiomas como este são úteis apenas para varrer do campo de análise comportamentos notadamente estranhos à racionalidade. Dito isto, quer-se partir do argumento de que clivagens do tipo "estabilização da inflação x crescimento econômico" produzem mais barulho do que luz para o debate sobre a política econômica. Dado que há larga evidência empírica de que países com melhores taxas de crescimento sustentado são também aqueles que apresentam um crescimento lento dos preços $^{1}$, parece mais adequado o debate sobre quais políticas permitem coordenar o crescimento econômico elevado com níveis baixos de inflação.

Fixado o ponto de partida, o que se pretende neste sustentar é que a agenda da política macroeconômica dos primeiros cinco meses do Governo Lula é, essencialmente, a mesma da maior parte do segundo mandato do governo FHC: regime de metas de inflação, câmbio flutuante e metas de superávit primário para o "dia-a-dia" da política econômica e uma agenda de reformas que melhorem a equação de financiamento de longo prazo do setor público brasileiro. Esse foi o core da agenda da política macroeconômica desde a crise de 99 e o abandono do regime de bandas cambiais. Aceitando o argumento da continuidade da agenda, este artigo pretende explorar algumas implicaçōes associadas a esta opção inicial do Governo Lula.

\footnotetext{
- Presidente da FEE e Professor de Economia da PUC/RS.

${ }^{1}$ Dornbusch (2003) apresenta um resumo destas evidências.
} 


\section{Os Fundamentos Macroeconômicos}

O tripé baseado no regime de metas de inflação, câmbio flutuante e metas de superávit foi o core da agenda da política macroeconômica desde a crise de 99 e o abandono do regime de bandas cambiais. De forma lógica sinalizava duas conseqüências inevitáveis, ao menos enquanto as reformas não viessem: i) a diminuição da dependência de capital externo exigiria um duro esforço na geração de superávits primários do governo central e ii) um eventual stress na taxa de câmbio exigiria um aperto na política monetária.

A primeira conseqüência exposta acima implica aceitar que a vulnerabilidade externa é uma manifestação de fragilidade de natureza fiscal e que elevados déficits em conta corrente revelam a baixa capacidade de geração de poupança interna do país ${ }^{2}$. Essa tese, a princípio, poderia ser considerada como eminentemente "ortodoxa" ou "clássica"3. No entanto, não há incompatibilidade ao pôr numa moldura keynesiana dinâmica o argumento de que a incapacidade constante de geração de poupança interna limita o crédito por conta das expectativas de longo prazo que afetam tanto a eficiência marginal do capital ( Keynes, cap. 11) quanto a taxa de juros monetária de curto prazo (Keynes, cap. 17) - e, conseqüentemente, impede que o equilíbrio entre o fluxo de investimentos e a poupança se dê apenas ex-post. O problema maior é compatibilizar a tese inicial com os argumentos pós-keynesianos de fragilização financei$\mathrm{ra}^{4}$ - os quais, aparentemente, davam o rumo do pensamento econômico que governava as críticas do Partido dos Trabalhadores ao antigo governo - , para os quais a fragilidade externa parece ser mais causa do que conseqüência da deterioração fiscal.

A segunda conseqüência é um resultado previsível quando convivem um regime de metas de inflação e a flutuação do câmbio: se o

\footnotetext{
${ }^{2}$ Seria uma feliz coincidência que anúncios de metas de superávits primários mais elevados ou augúrios de sucesso na condução da reforma da previdência provoquem recuos acentuados no Risco Brasil?.

${ }^{3} \mathrm{O}$ sentido da ortodoxia seria a aceitação de um mecanismo de fundos emprestáveis regulando a restriçāo de financiamento externo do país.

${ }^{4}$ Não cabe aqui uma discussão mais aprofundada sobre a consistência de tais análises, a não ser comentar que têm em comum a hipótese de que os desequilíbrios externos, ao fazerem que o país passe de uma situação hedge para ponzi (Minsky, 1986), é que provocam a elevação das taxas internas de juros e a deterioração fiscal. Esta parece ser a linha de causalidade estabelecida, ainda que os defensores de tal argumento não recorram a uma metodologia de testes no sentido econométrico (ver Porcile, 2002).
} 
câmbio sobe demasiadamente, a política monetária não pode assistir passivamente o repasse para os preços sob pena de ficar comprometida a credibilidade da autoridade monetária - caso contrário, ou se abandona o câmbio livre ou se abandona o programa de metas de inflação. Estas duas últimas alternativas apresentam dilemas conhecidos para a política econômica.

A oscilação acentuada do câmbio vem despertando críticas naqueles que defendem a volta de algum controle sobre os fluxos de oferta e demanda da moeda estrangeira. Quando o dólar atingiu as cotaçōes máximas, o argumento do controle era que seria possível evitar os impactos inflacionários minimizando o ajuste recessivo. Quando o dólar caiu acentuadamente, após o início do novo governo, a justificativa do controle era que seria necessário evitar uma queda futura nos saldos da balança comercial. Não é preciso ser muito arguto para perceber que tais argumentos, por si só, já expõem as limitações de um controle eficiente do câmbio: não pode ser nem tão elevado que comprometa a estabilidade de preços e nem tāo baixo que agrave o déficit em transaçōes correntes. Foi exatamente isso que o BC tentou entre 1994 e o início de 1999, quando a pressão vendedora no mercado de câmbio se mostrou incontrolável e ameaçou destruir as reservas da autoridade monetária. Moral da história: com pequenas pressões sobre a volatilidade do câmbio, há maior chance de sucesso para um sistema administrado do que quando a pressão aumenta. Isto significa que quando mais se precisa de um câmbio sob controle administrado, é quando é menos provável que isso possa ocorrer.

Quanto a um possível abandono do regime de metas de inflação ou a uma flexibilização maior dos limites superiores das metas, os defensores de tal proposta sustentam que a política monetária poderia ser menos rígida e, com isso, permitir um maior crescimento econômico no curto prazo. Sem entrar na tradicional discussão sobre o formato da curva de Phillips, a proposta acima traria o custo imediato da perda de credibilidade da autoridade monetária, o que poderia inviabilizar uma iniciativa imediata de redução de juros. Além disso, se o objetivo é elevar a taxa de crescimento de longo prazo pode ser preferível aceitar uma taxa de sacrifício maior no curto prazo. Em resumo, após o abandono da "âncora cambial" o regime de metas de inflação vem desempenhando um decisivo papel na ancoragem das expectativas inflacionárias. $\mathrm{Na}$ impossibilidade de se retornar ao modelo anterior de coordenação das expecta- 
tivas, parece ser muito arriscado o abandono do programa de metas ou o seu excessivo relaxamento.

Os fundamentos gerais da atual política macroeconômica não deixam de ser surpreendentes pelo histórico do discurso crítico que muitos membros importantes do atual governo sempre empregaram em relação à política macroeconômica anterior. Na prática, os atuais fundamentos da política econômica revelam a crença de que cabe ao BC a preocupação exclusiva com o controle inflacionário, e que a capacidade de aumentar o crescimento econômico sustentável de longo prazo deve exigir a eliminação de restrições estruturais para a elevação da formação de poupança interna.

\section{O Reforço da Ortodoxia}

A manutenção da agenda da política macroeconômica, descrita acima, revela uma curiosa vicissitude: a política que se vem mantendo no atual governo, e que se argumenta ser, na essência, a do segundo mandato do governo FHC, é acentuadamente mais ortodoxa do que a praticada entre 1995 e 1998. Neste último período, a flutuação do câmbio foi administrada, e a política fiscal mostrou ser muito mais frouxa. Salvo melhor juízo, seria estranho não reconhecer que o sentido da mudança foi da heterodoxia para a ortodoxia. É evidente que o cenário externo explicou muito da mudança adotada a partir de 1999. Todavia, o reconhecimento desta evidência não altera o conteúdo da mudança, apenas explica como foi possível realizá-la. A curiosidade, ou surpresa, é a manutenção de uma política que migrou de uma heterodoxia relativa para uma ortodoxia relativa justamente por parte de um partido historicamente não identificado com tal argumento teórico. E não parece haver margem para a dúvida de que há continuidade na agenda. Basta constatar que frases como "A reforma da previdência é vital para o financiamento saudável do setor público", "A taxa de juros só poderá cair quando a inflação recuar" ou "Para que haja crescimento sustentado é preciso que haja queda sustentada da taxa de juros; não adianta baixar a taxa hoje e ter que subi-la amanhã" não soam como novas e alternativas afirmações.

Vale a pena destacar o enfoque de que a continuidade empregada pelo governo, pelo menos até aqui, é uma continuidade de agenda e não de um ou outro instrumento de política 
macroeconômica. Nesta agenda, os instrumentos da política de curto prazo e a sua dosagem são também justificados pelos objetivos de longo prazo!!! A defesa das reformas é insistentemente associada à possibilidade de uma redução futura da taxa real de juros de longo prazo e de uma menor necessidade de geração de superávits primários. Sendo assim, as ações e o discurso devem sinalizar que a política de curto prazo é boa porque permite se chegar a políticas de crescimento consistente no longo prazo. Por outro lado, afirmaçōes de que, em algum momento à frente, será feita a ruptura ou a mudança do core da política econômica não são consistentes com a defesa da atual política. De forma mais objetiva: ou a política atual é boa porque dá respostas adequadas a problemas econômicos de forma consistente no tempo ou ela é ruim e deve ser abandonada. Dizer que há um tempo para a estabilização e a tranqüilidade dos mercados e que depois haverá uma política de crescimento e desenvolvimento não inova, nem diferencia, em nada, a atual política em relação a sua antecessora. Esse é um discurso que cabia antes, cabe agora e caberá na frente, sob o abrigo do mesmo leque das políticas macroeconômicas executadas hoje.

A confirmação da opção ortodoxa para a política econômica poder ser confirmada pela escolha dos seus principais atores. A composição do núcleo central das decisões de política econômica, tanto no $\mathrm{BC}$ como no Ministério da Fazenda, é claramente reveladora da atual opção do governo. Excetuando a dupla Meirelles-Palocci, economistas da PUC/RIO e da FGV/RIO ocupam todos os cargos relevantes para a tomada de decisão sobre os instrumentos de política monetária, cambial e fiscal. O que envolveria uma guinada mais à frente? A troca de todos esses policy makers? Essa opção não parece algo provável, muito menos recomendável.

Dizer que a atual política macroeconômica é ruim, mas necessária, sugere um certo grau de esquizofrenia ou de pura confusão no argumento. Esquizofrenia, por se achar que a política macroeconômica boa, a que virá com a mudança, é tão boa quanto incapaz de responder a problemas triviais de ajustamento macroeconômico como os que agora são enfrentados. A confusão fica por conta da suposição implícita de que o que mudará, se tudo der certo, será a política "nova" e não o ambiente econômico facilitado pela consistência da política "antiga". Se os juros puderem cair de forma sustentada e o país depender menos do capital externo de curto prazo será em função das atuais e corretas açōes do $\mathrm{BC}$ e do 
Ministério da Fazenda e pelo eventual sucesso das reformas. Poderá se trilhar, então, um caminho virtuoso de crescimento sustentado. Neste cenário otimista, teria ocorrido uma "mudança" ou "guinada" na política econômica? A resposta é não, ao menos no conteúdo. Mas nada que alguns contorcionistas do discurso político governamental não possam justificar. Do outro lado, justiça se faça. Há os que criticaram a "antiga" política econômica e que criticam a atual pelas mesmas razões: julgavam ela ruim no passado e continuam julgando-a ruim no presente. Há também os que se converteram aos méritos da "nova" política. Em ambos os casos, não há esquizofrenia, nem confusão. A primeira situação é uma questão de manutenção de convicções teóricas. A segunda é uma mudança de opiniáo. As duas são absolutamente normais no debate científico.

\section{As Chances de Sucesso da Atual Agenda}

Mas se o argumento, aqui, é de que a agenda é a mesma, haveria alguma mudança significativa até agora? A tese é de que há, e ela é muito significativa. A chance de que a agenda seja efetivamente executada já no início do Governo Lula é muito maior do que a existia no segundo mandato do Governo FHC. Fazendo uso da teoria dos jogos e pensando a política econômica e as reformas em termos do ambiente institucional vigente, há condições iniciais mais favoráveis para que ocorra um equilíbrio cooperativo, anteriormente improvável. A mudança das condições iniciais em jogos entre governo e oposição pode ser um caso típico de transposição de jogadores em períodos imediatos a eleições, como nos jogos analisados em Drazen (2000) e Fundenberg (2000). Entre as condições iniciais, podem ser destacadas uma de natureza econômica e duas de natureza política. A primeira condição é a existência de um ambiente econômico mais estável e menos incerto (num sentido de incerteza probabilística e não knightiana), fruto da confirmação da continuidade das políticas macroeconômicas. A respeito disso é importante ressaltar que a boa e calma transição realizada entre 2002 e 2003 pode gerar um importante ganho no longo prazo: a diminuição do grau de incerteza em futuras eleiçōes na jovem democracia brasileira. Quanto às condições políticas, que parecem ser as mais importantes para o sucesso de implantação da agenda, a primeira é a forma como o Presidente Lula vem utilizando seu capital político her- 
dado com as eleiçōes, e a segunda é a nova composição entre governo e oposição. Valendo-se das boas recomendações da ciência política, o Presidente Lula manifesta clara intenção de utilizar o atual nível de capital político - naturalmente elevado, após as eleições para enfrentar os elevados custos com a defesa da política macroeconômica e, em especial, com a defesa das reformas constitucionais. Além disso, há uma composição entre governo e oposição claramente mais favorável à implementação da agenda do governo. O principal partido opositor à agenda anterior passa a ser, agora, governo, e a defender uma agenda que é muito próxima daquela que era defendida pelos partidos que, hoje, são oposição. Voltando à economia das instituiçōes e a teoria dos jogos, é politicamente racional esperar que subgrupos no governo e na oposição não devam convergir para um equilíbrio cooperativo de valor mais elevado para a sociedade. Todavia, os ganhos (pay-offs) atuais, associados ao eventual equilíbrio cooperativo, são maiores, tanto para o novo governo como para a nova oposição. Essa é a razão para se esperar que tal equilíbrio possa ocorrer.

\section{A Continuidade da Agenda e o Crescimento Econômico}

A manutençāo de uma coordenação entre as políticas monetária, fiscal e cambial - para preservar a estabilidade de preços e o equilíbrio na balança de pagamentos, no curto prazo - e o sucesso na aprovação de reformas - para flexibilizar a restrição fiscal do setor público - são importantes condições iniciais para a retomada de um ciclo virtuoso e duradouro de crescimento econômico. Como o nosso nível de formação de poupança interna ainda é muito baixo, ainda estamos longe de imaginar uma situação próxima a uma golden rule, como no modelo de Solow. Além disso, os mercados financeiros parecem sinalizar que a possibilidade de as gerações futuras financiarem as geraçōes presentes é cada vez menor. Assim, recuperar a capacidade de geração de poupança interna no presente parece ser um bom ponto de partida para o início de uma trajetória de crescimento maior e mais prolongado.

Como o nível de poupança interna não exaure a explicação da dinâmica de crescimento de longo prazo, ainda será necessário uma série de esforços para aumentar a produtividade média da economia e melhorar a eficiência do sistema institucional. As tarefas não 
são pequenas. Vão desde a rápida melhoria na qualidade do sistema de ensino até o desenho de um sistema judiciário mais eficiente. Essa parece ser uma agenda bastante ampla e que provavelmente exija uma segunda rodada de reformas constitucionais, além de um leque de políticas públicas mais abrangentes do que o discutido até aqui. Sendo assim, a atual agenda da política econômica pode ser vista como necessária, mas não suficiente, para representar uma agenda de crescimento econômico de longo prazo. A consistência temporal dessa agenda ainda será testada ao longo dos próximos anos.

\section{Referências Bibliográficas}

DRAZEN, A. (2000). Political Economy in Macroeconomics, Princeton University Press. New Jersey.

DORNBUSCH, R. (2003) Chaves para a Prosperidade. Record. Rio de Janeiro

CARTA DE CONJUNTURA FEE (2003). A Política Econômica em Debate: Continuidade ou Mudança? FEE, ano 12, n.3, Porto Alegre.

FUNDENBERG, D. e TIROLE, J.(2000) Game Theory. The MIT Press. London.

KEYNES, J.M (1990). A Teoria Geral do Emprego, do Juro e da Moeda. Atlas. São Paulo.

MINSKY, H. Stabilizing an Unstable Economy. Yale University Press, 1986.

PORCILE,G., CURADO,M e BAHRY,T. (2002) Crescimento com Restrição no Balanço de Pagamentos e Fragilidade Financeira: Uma Abordagem Macroeconômica para a América Latina. V Encontro de Economia da Região Sul. Florianópolis. 